\title{
Diastereomer-Specific Uptake, Translocation, and Toxicity of Hexabromocyclododecane Diastereoisomers to Maize
}

\author{
Tong $\mathrm{Wu}$, Sen Wang, Honglin Huang, and Shuzhen Zhang* \\ State Key Laboratory of Environmental Chemistry and Ecotoxicology, Research Center for Eco-Environmental Sciences, Chinese \\ Academy of Sciences, Beijing 100085, China
}

ABSTRACT: Hexabromocyclododecane (HBCD), a brominated flame retardant, has become a ubiquitous contaminant due to its wide application, persistence, and toxicity. $\mathrm{HBCD}$ diastereoisomers have different physical and chemical properties and may differ in their bioaccumulation and toxicity in plants. Accumulation and toxicity of $\alpha$-, $\beta$-, and $\gamma$-HBCDs in maize were investigated in the present study. The accumulation was in the order $\beta$ - $\mathrm{HBCD}>\alpha$ - $\mathrm{HBCD}>\gamma$-HBCD in roots and $\beta$-HBCD $>\gamma$ $\mathrm{HBCD}>\alpha$-HBCD in shoots. Both the inhibitory effect of the diastereoisomers on the early development of maize and the intensities of hydroxyl radical and histone $\mathrm{H} 2 \mathrm{AX}$ phosphorylation in maize exposed to $2 \mu \mathrm{g} \mathrm{L}^{-1} \mathrm{HBCD}$ followed the order $\alpha$ $\mathrm{HBCD}>\beta$-HBCD $>\gamma$-HBCD, indicating the diastereomer-specific oxidative stress and DNA damage in maize. It was further confirmed that the generation of reactive oxygen species was one, but not the only, mechanism for DNA damage in maize exposed to HBCDs.

KEYWORDS: hexabromocyclododecane (HBCD) diastereoisomer, plant accumulation, ROS generation, DNA damage

\section{INTRODUCTION}

Hexabromocyclododecane (HBCD) is the most widely used cycloaliphatic brominated flame retardant (BFRs) as an additive flame retardant in polystyrene foams and upholstery textiles. ${ }^{1}$ Recent global annual production estimates for HBCD are not available, but the total production volume was about $16700 \mathrm{t}$ in 2001, which was behind only tetrabromobisphenol-A ( $>130000$ $\mathrm{t})$ and decabromodiphenyl ether $(56100 \mathrm{t}) .^{2}$ Due to its persistence and bioaccumulation properties, HBCD has been detected in a wide variety of biota and abiotic samples, and its burdens on the environment have risen rapidly over the past decade. $^{3-6} \mathrm{HBCD}$ in the environment is of considerable concern because it has been confirmed as a hepatic enzyme inducer, ${ }^{7}$ developmental neurotoxicant, ${ }^{8}$ and endocrine disruptor. ${ }^{9}$ However, there are currently no restrictions on $\mathrm{HBCD}$ production and use.

Commercial (technical) HBCD is a chemical mixture primarily consisting of three diastereoisomers, $\alpha$-, $\beta$-, and $\gamma$ HBCDs $(\alpha, 1-12 \% ; \beta, 10-13 \% ; \gamma, 75-89 \%) .{ }^{10}$ Although the $\gamma$-HBCD is predominant in commercial production, the $\alpha$ $\mathrm{HBCD}$ is usually the highest in biotic environment, whereas the $\gamma$-HBCD has been reported as the dominant diastereoisomer in sediments. ${ }^{11-13}$ Individual diastereoisomers exhibit different physical and chemical properties, resulting in their different bioaccumulation and metabolic fates. Therefore, there is a need to elucidate the fate of $\mathrm{HBCD}$ in the environment as individual diastereoisomers.

Plant uptake of organic contaminants is an important process in the consideration of the risks associated with land contamination, the role of vegetation in the global cycling, and the potential to contaminate the food chain. ${ }^{14}$ Despite their ubiquitous exposure to plants, there is very limited knowledge about plant uptake and phytotoxicity of HBCD diastereoisomers. To our knowledge, the only available research on plant uptake of HBCDs was conducted recently by $\mathrm{Li}$ et al., ${ }^{15}$ who reported the diastereomer-specific distribution of HBCDs in cabbage and radish tissues with the predominance of $\gamma$ HBCD in roots and $\alpha$-HBCD in shoots. For a better understanding of the biological behavior of a chemical, an examination of its toxic properties is indispensable. Unfortunately, toxicity information on HBCD diastereoisomers is limited; the reported studies are solely limited to their animal and cell toxicities, ${ }^{16,17}$ and up to now there have been no studies on HBCD phytotoxicity.

When exposed to contaminants, plants often suffer oxidative stress caused by the generation of reactive oxygen species (ROS). Excessive ROS can further induce lipid, protein, and DNA oxidation and subsequent cell death. ${ }^{18}$ ROS-derived DNA oxidation will result in altered bases and damaged sugar residues, leading to DNA single- and double-strand breaks (DSBs). ${ }^{19}$ Therefore, the level of DNA damage can be used to effectively evaluate the relationship of oxidative stress and genotoxicity in plants. Phosphorylation of histone $\mathrm{H} 2 \mathrm{AX}(\gamma$ $\mathrm{H} 2 \mathrm{AX}$ ) at serine 139 occurs after DNA DSBs and is probably the earliest cellular response to this lesion. ${ }^{20}$ Because of the rapid induction of $\gamma-\mathrm{H} 2 \mathrm{AX}$ and the correspondence between the number of $\gamma$-H2AX foci and the number of DSBs, $\gamma$-H2AX has become a gold standard to detect the presence of DSBs. The high sensitivity of the $\gamma$-H2AX foci assay has enabled researchers to measure low levels of DNA damage. ${ }^{21}$

Therefore, a hydroponic experiment was conducted in the present study to investigate diastereomer-specific uptake, translocation, and toxicity of HBCDs in maize. Timedependent accumulations of $\alpha$-, $\beta$-, and $\gamma$-HBCDs in maize were measured. Toxicity of HBCD diastereoisomers in maize

Received: June 21, 2012

Revised: August 7, 2012

Accepted: August 10, 2012

Published: August 10, 2012 

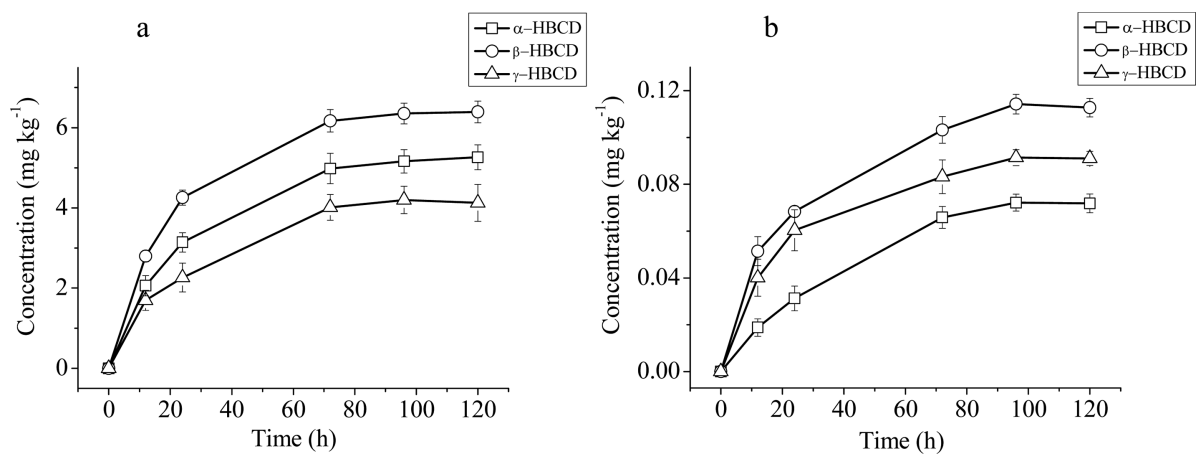

Figure 1. Time-dependent accumulation of HBCDs in roots (a) and shoots (b) of maize exposed to $\alpha$-, $\beta$-, and $\gamma$-HBCDs on a dry weight basis. Error bars represent SD values.

was examined by determining their toxic influence on the early growth and development of maize. ROS generation in maize exposed to HBCD diastereoisomers was then determined by electron paramagnetic resonance (EPR) spectroscopy. The level of phosphorylated histone $\mathrm{H} 2 \mathrm{AX}$, a reliable indicator of DNA DSBs, was examined to investigate genotoxicity in maize induced by HBCD diastereoisomers. The results of this study would offer useful information for a more comprehensive assessment of the environmental behaviors of $\mathrm{HBCD}$ diastereoisomers.

\section{MATERIALS AND METHODS}

Chemicals. The standards of $\alpha$-, $\beta$-, and $\gamma$-HBCDs were purchased from AccuStandard (New Haven, CT, USA) and the ${ }^{13} \mathrm{C}$-labeled $\alpha$-, $\beta$-, and $\gamma$-HBCDs standards were obtained from Cambridge Isotope Laboratories, Inc. (Andover, MA, USA). Dimethyl sulfoxide (DMSO, purity $>99.9 \%$ ) and $\alpha$-phenyl- $N$-tert-butylnitrone ( $\mathrm{PBN}$, purity > 98\%) were obtained from Sigma-Aldrich Co. (St. Louis, MO, USA). Anhydrous sodium sulfate $\left(\mathrm{Na}_{2} \mathrm{SO}_{4}\right)$, silica gel, and alumina (100-200 mesh) were washed with hexane and used after heating overnight at $150^{\circ} \mathrm{C}$. Other solvents and chemicals used were of analytical or HPLC grade.

Seeds and Plant Exposure to HBCDs. Test solutions of $2 \mu \mathrm{g} \mathrm{L}^{-1}$ were prepared by $\alpha$-, $\beta$-, and $\gamma$-HBCDs standards, aiming to set the initial concentrations lower than their water solubilities (48.8, 14.7, and $2.1 \mu \mathrm{g} \mathrm{L}^{-1}$ for $\alpha$-, $\beta$-, and $\gamma$-HBCDs, respectively). ${ }^{22}$ Maize (Zea mays $\mathrm{L}$.) was used as the test plant, and the seeds were obtained from the Chinese Academy of Agricultural Sciences, Beijing, China. Prior to germination, the seeds were surface-sterilized in $3 \%(\mathrm{v} / \mathrm{v}) \mathrm{H}_{2} \mathrm{O}_{2}$ for 10 min and rinsed thoroughly with deionized water. Seed germination was tested on filter paper placed in Petri dishes and moistened with 60 $\mathrm{mL}$ of test solutions. Control was obtained by moistening the filter papers with $60 \mathrm{~mL}$ of deionized water. One hundred seeds after sterilization were placed in each dish, covered by a lid, and incubated at $27 \pm 0.5{ }^{\circ} \mathrm{C}$ in the dark. After $96 \mathrm{~h}$, the proportion of germinated seeds was counted. Seeds were considered to have germinated when both the radicle and coleoptile lengths were over half the seed size.

After normal germination for 4 days, five uniform seedlings were transferred to each colored vitreous pot containing $200 \mathrm{~mL}$ of test solution to investigate the uptake and toxicity of HBCDs in maize. Pots were kept in a growth chamber with a controlled environment at a light intensity of $250 \mu \mathrm{mol} \mathrm{m} \mathrm{m}^{-2} \mathrm{~s}^{-1}$ provided by supplementary illumination with a photoperiod of $14 \mathrm{~h}$ each day, at a $25 / 20^{\circ} \mathrm{C}$ day/ night temperature regimen and a relative humidity of $60-70 \%$. The seedlings were repositioned daily to minimize spatial differences in illumination and temperature. Unplanted control and blank control (without $\mathrm{HBCD}$ exposure) were included. Test solutions were renewed every day, and all treatments were set up in triplicate.

UPLC Determination of HBCDs in Plant Tissues. The harvested plants were separated into roots and shoots, rinsed thoroughly with deionized water, and blotted with filter paper. Plant samples were then frozen at $-50{ }^{\circ} \mathrm{C}$ overnight and freeze-dried for 48 $\mathrm{h}$ in a lyophilizer (FD-1, Beijing Boyikang Instrument Ltd., Beijing, China). The dried samples were chopped finely and stored in glass containers at $-20{ }^{\circ} \mathrm{C}$ before extraction.

Extraction and cleanup of plant samples for $\mathrm{HBCD}$ analysis were based on the method of Zhang et al. ${ }^{23}$ with some modifications. Each sample (0.1-0.5 g dry weight) was Soxhlet extracted for $24 \mathrm{~h}$ using $100 \mathrm{~mL}$ of hexane/acetone $(1: 1, \mathrm{v} / \mathrm{v})$ at $65^{\circ} \mathrm{C}$ after being spiked with ${ }^{13} \mathrm{C}-\alpha$-HBCD and ${ }^{13} \mathrm{C}-\gamma$-HBCD. The concentrated extract was then cleaned up on a multilayer silica gel/alumina column packed with anhydrous sodium sulfate $(5 \mathrm{~g})$, neutral silica ( $2 \mathrm{~g}$, 3\% deactivated), acidic silica (5 g, $44 \%$ sulfuric acid), neutral silica (2 g, $3 \%$ deactivated), neutral alumina ( $5 \mathrm{~g}, 3 \%$ deactivated), and anhydrous sodium sulfate $(5 \mathrm{~g})$ from top to bottom. HBCD was eluted with 150 $\mathrm{mL}$ of hexane/dichloromethane $(1: 1, \mathrm{v} / \mathrm{v})$ and evaporated to $1 \mathrm{~mL}$. After concentration to near dryness under gentle nitrogen gas, the extract was spiked with ${ }^{13} \mathrm{C}-\beta$ - $\mathrm{HBCD}$ as an internal standard and adjusted to $400 \mu \mathrm{L}$ with methanol.

The extracted samples were analyzed using an ultra highperformance liquid chromatograph coupled to a triple-quadrupole mass spectrometer (UPLC-MS/MS). Chromatographic separation of HBCD diastereoisomers was performed on an UPLC (Waters Acquity UPLC system, Waters, Milford, MA, USA) with a column of Waters Acquity UPLC BEH $\mathrm{C}_{18}(50 \times 2.1 \mathrm{~mm}$, i.d., $1.7 \mu \mathrm{m}$ particle size $)$. A mobile phase of (A) $10 \mathrm{mM}$ ammonium acetate and (B) methanol at a flow rate of $0.2 \mathrm{~mL} \mathrm{~min}^{-1}$ was applied for elution of the target compounds. The elution program started with $50 \% \mathrm{~A}$ and was ramped linearly to $15 \% \mathrm{~A}$ in $9 \mathrm{~min}$, held for $4 \mathrm{~min}$, followed by a linear decrease to $0 \% \mathrm{~A}$ in $1 \mathrm{~min}$, and held for $5 \mathrm{~min}$. Then the mobile phase composition returned to the initial conditions in $2 \mathrm{~min}$ and equilibrated for a further $5 \mathrm{~min}$. A Waters Quattro Premier XE triple-quadrupole mass spectrometer equipped with an ESI source (Waters) was used. The MS system was operated in the electrospray (ESI) negative ionization and multiple reaction monitoring (MRM) mode. The MRM transitions monitored for native HBCDs were $639.7 \rightarrow 79.0$ and $651.5 \rightarrow 79.0$ for the ${ }^{13} \mathrm{C}$-labeled $\mathrm{HBCD}$, respectively. The conditions for the MS system were optimized as follows: cone voltage, $20 \mathrm{~V}$; capillary voltage, $3.5 \mathrm{kV}$; desolvation temperature, 350 ${ }^{\circ} \mathrm{C}$; source temperature, $110{ }^{\circ} \mathrm{C}$; nebulizing gas flow, $400 \mathrm{~L} \mathrm{~h}^{-1}$; cone gas flow, $50 \mathrm{~L} \mathrm{~h}^{-1}$; and collision energy, $15 \mathrm{eV}$.

For every batch of six samples, a solvent blank was added to ensure that the samples were free of contamination. Matrix effects on signal intensity of UPLC-MS were minimized using ${ }^{13} \mathrm{C}-\alpha$ - and ${ }^{13} \mathrm{C}-\gamma$ HBCDs as the surrogate standards and ${ }^{13} \mathrm{C}-\beta-\mathrm{HBCD}$ as internal standard. The limits of detection (LOD) were $0.001 \mathrm{mg} \mathrm{kg}^{-1}$ on dry weight basis. Recovery values ranged from 71.7 to $89.3 \%$, with a relative standard deviation $(\mathrm{RSD})<10 \%$. No HBCD was found in the blank plants.

EPR Analysis of ROS. Maize roots and shoots were subjected to the detection of ROS generated after exposure to HBCDs in solution. After rinsing with ice-cold $0.1 \mathrm{M} \mathrm{CaCl}_{2}$ solution and blotting with filter paper, plant samples were weighed $(0.5 \mathrm{~g})$ and homogenized in a mortar with $1.0 \mathrm{~mL}$ of freshly prepared solution of $100 \mathrm{mM} \mathrm{PBN}$ 
Table 1. Time-Dependent Inhibition Rates (IR) of GER, RB, SB, RE, and SE to Maize after Exposure to $\alpha$-, $\beta$-, and $\gamma$-HBCDs ${ }^{a}$

\begin{tabular}{|c|c|c|c|c|c|c|}
\hline \multirow[b]{2}{*}{ compd } & \multirow[b]{2}{*}{ time $(\mathrm{h})$} & \multicolumn{5}{|c|}{ IR (\%) } \\
\hline & & GER & $\mathrm{RB}$ & SB & RE & SE \\
\hline \multirow[t]{5}{*}{$\alpha$-HBCD } & 0 & $0.00 \pm 2.44 \mathrm{a}$ & $0.00 \pm 0.17$ & $0.00 \pm 0.13$ & $0.00 \pm 0.24$ & $0.00 \pm 0.25$ \\
\hline & 12 & & $0.35 \pm 0.13$ & $0.24 \pm 0.15$ & $0.31 \pm 0.09$ & $0.18 \pm 0.11$ \\
\hline & 24 & & $3.74 \pm 0.25$ & $2.86 \pm 0.19$ & $3.49 \pm 0.24$ & $1.94 \pm 0.33$ \\
\hline & 72 & & $4.98 \pm 1.71$ & $3.63 \pm 0.36$ & $4.52 \pm 0.67$ & $2.08 \pm 1.77$ \\
\hline & 96 & $29.44 \pm 2.44 b$ & $9.66 \pm 1.90$ & $6.55 \pm 1.13$ & $8.65 \pm 0.76$ & $5.75 \pm 1.26$ \\
\hline \multirow[t]{5}{*}{$\beta$-HBCD } & 0 & & $0.00 \pm 0.43$ & $0.00 \pm 0.25$ & $0.00 \pm 0.35$ & $0.00 \pm 0.36$ \\
\hline & 12 & & $0.30 \pm 0.19$ & $0.14 \pm 0.04$ & $0.21 \pm 0.08$ & $0.08 \pm 0.07$ \\
\hline & 24 & & $2.94 \pm 0.15$ & $1.37 \pm 0.19$ & $2.18 \pm 0.29$ & $1.24 \pm 0.38$ \\
\hline & 72 & & $3.35 \pm 1.61$ & $1.72 \pm 0.87$ & $2.38 \pm 0.84$ & $1.58 \pm 1.53$ \\
\hline & 96 & $14.09 \pm 2.44 c$ & $6.00 \pm 1.94$ & $4.33 \pm 0.46$ & $4.86 \pm 1.53$ & $3.64 \pm 1.08$ \\
\hline \multirow[t]{5}{*}{$\gamma$-HBCD } & 0 & & $0.00 \pm 0.24$ & $0.00 \pm 0.17$ & $0.00 \pm 0.47$ & $0.00 \pm 0.21$ \\
\hline & 12 & & $0.23 \pm 0.11$ & $0.09 \pm 0.05$ & $0.19 \pm 0.09$ & $0.00 \pm 0.10$ \\
\hline & 24 & & $1.62 \pm 0.27$ & $1.07 \pm 0.24$ & $1.13 \pm 0.31$ & $0.92 \pm 0.27$ \\
\hline & 72 & & $3.00 \pm 0.33$ & $1.94 \pm 0.27$ & $2.58 \pm 0.37$ & $0.73 \pm 0.51$ \\
\hline & 96 & $11.27 \pm 4.23 c$ & $5.46 \pm 1.21$ & $4.10 \pm 0.34$ & $4.15 \pm 0.37$ & $2.86 \pm 1.01$ \\
\hline \multicolumn{7}{|c|}{ significance of } \\
\hline \multicolumn{2}{|c|}{ time } & & $* *$ & $* *$ & $* *$ & $* *$ \\
\hline \multicolumn{2}{|c|}{ diastereoisomer } & & $* *$ & $* *$ & $* *$ & $* *$ \\
\hline \multicolumn{2}{|c|}{ time $\times$ diastereoisomer } & & $* *$ & $* *$ & $* *$ & $* *$ \\
\hline
\end{tabular}

${ }^{a}$ Different letters represent statistically significant difference between different diastereoisomers at $p<0.05$, whereas $* *$ represents significant effect at $p<0.05$.

(dissolved in DMSO) in an ice bath. Then the homogenates were incubated at $37{ }^{\circ} \mathrm{C}$ for $15 \mathrm{~min}$ and centrifuged at $4500 \mathrm{rpm}$ for $3 \mathrm{~min}$ at $4{ }^{\circ} \mathrm{C}$. The supernatant $(30 \mu \mathrm{L})$ was transferred to a capillary tube with a diameter of $1.0 \mathrm{~mm}$ for EPR analysis. The EPR spectra were recorded with a Bruker ESP 300 spectrometer (Bruker, Germany) at room temperature. The operation conditions were as follows: microwave power, $20 \mathrm{~mW}$; microwave frequency, $9.7 \mathrm{GHz}$; center field, $347 \mathrm{mT}$; scan range, $10 \mathrm{mT}$; modulation frequency, $100 \mathrm{kHz}$; modulation amplitude, $0.25 \mathrm{mT}$; and receiver gain, $2 \times 10^{4}$ scans.

Histone Extraction and DNA Damage Analysis. Maize plants exposed to HBCDs were rinsed thoroughly with distilled water, blotted with filter paper, and separated into roots and shoots. Fresh sample $(1.0 \mathrm{~g})$ was homogenized in $9 \mathrm{~mL}$ of extraction buffer $(0.2 \mathrm{M}$ $\mathrm{NaH}_{2} \mathrm{PO}_{4} \cdot \mathrm{Na}_{2} \mathrm{HPO}_{4}, \mathrm{pH}$ 7.4) in an ice bath. Then the homogenates were centrifuged at $4000 \mathrm{rpm}$ for $15 \mathrm{~min}$ at $4{ }^{\circ} \mathrm{C}$, and the supernatant was collected. The H2AX phosphorylation level in histone samples was analyzed with a plant $\gamma$-H2AX enzyme-linked immunosorbent assay (ELISA) kit (RB, USA).

Statistical Analysis. All results are expressed as the mean \pm standard deviation (SD) of triplicates. Statistical analysis was performed by Microsoft Excel, Origin 7.5, and SPSS 13.0 variance analysis software. One-way and two-way ANOVAs with Turkey's multiple-comparison tests were used to assess differences among samples at $p<0.05$.

\section{RESULTS AND DISCUSSION}

Uptake and Accumulation of HBCDs in Maize. The initial fast uptake caused a sharp increase in the concentrations of $\alpha$-, $\beta$-, and $\gamma$-HBCDs in maize roots and shoots, and their accumulation reached an apparent equilibrium within $96 \mathrm{~h}$ (Figure 1). Concentrations of the three diastereoisomers were much higher in maize roots than in shoots, and the apparent equilibrium concentrations of $\alpha$-, $\beta$-, and $\gamma$-HBCDs were 5.3, 6.4 , and $3.2 \mathrm{mg} \mathrm{kg}^{-1}$ in roots and $0.07,0.11$, and $0.09 \mathrm{mg} \mathrm{kg}^{-1}$ in shoots on a dry weight basis, respectively. The accumulation of $\mathrm{HBCD}$ diastereoisomers was in the order $\beta$-HBCD $>\alpha$ $\mathrm{HBCD}>\gamma$-HBCD in roots and $\beta$-HBCD $>\gamma$ - $\mathrm{HBCD}>\alpha$ -
HBCD in shoots. $\beta$-HBCD was the prominent diastereoisomer in both roots and shoots, and the concentration of $\gamma$-HBCD was lower in roots but higher in shoots compared with that of $\alpha$-HBCD. These results suggest that the uptake and translocation of HBCD in maize was diastereomer-selective.

Previous studies have demonstrated that $\alpha$ - or $\gamma$-HBCD was the dominant and $\beta$-HBCD was a minor diastereoisomer in many environmental samples. For example, $\alpha$-HBCD was reported to be the major diastereoisomer in the tissues of organisms such as fish, bird, and marine mammals, ${ }^{11,12,24}$ whereas $\gamma$-HBCD was found to be the dominant diastereoisomer in sediments from the Western Scheldt Estuary and the Detroit River. ${ }^{12,25}$ However, it is necessary to note that either environmental matrices or wild animals sampled and analyzed in these studies were exposed to the technical HBCD with the $\gamma$-diastereoisomer as main component followed by the $\alpha$ - and then the $\beta$-diastereoisomers. Until now, little has been known about diastereomer-specific behavior of HBCDs in plants. The only published research to date on plant uptake and accumulation of HBCD showed predominant accumulations of $\gamma$-diastereoisomer in roots and $\alpha$-diastereoisomer in shoots of cabbage and radish after exposure to the technical HBCD, and the $\beta$-diastereoisomer was present at a considerably low level in the plant tissues. ${ }^{15}$ Possible explanations in all of these studies may come from diastereomer-specific uptake and translocation of HBCDs and a shift in the diastereoisomer pattern in the organism or environment. In the present study, possible isomerization products were analyzed, and no isomerization of any HBCD diastereoisomer was observed in maize, suggesting diastereoisomer transformation did not occur in maize plants after exposure for $120 \mathrm{~h}$. The time-dependent accumulation represents a balance between the uptake and elimination processes. The higher accumulation level of $\beta$-HBCD indicates that this diastereoisomer is more easily taken up by maize compared with $\alpha$ - and $\gamma$-HBCDs. The results offer useful 
information for researchers to investigate the translocation and isomerization of HBCD diastereoisomers in plants.

Diastereomer-Specific Effects of HBCDs on Maize Growth. Exposure to HBCDs at $2 \mu \mathrm{g} \mathrm{L}^{-1}$ led to the inhibition of maize growth, and the relative inhibition rates on seed germination (GER), root biomass (RB), shoot biomass (SB), root elongation (RE), and shoot elongation ( $\mathrm{SE}$ ) increased with increasing exposure time (Table 1 ). The highest inhibition rates were observed at the exposure time of $96 \mathrm{~h}$. Seed germination was the most sensitive to the three HBCD diastereoisomers. Seed germination relies almost exclusively on seed reserves for the supply of respiration metabolites as well as other anabolic reactions. Starch is quantitatively the most abundant storage in seeds, and available evidence has indicated that seed starch is degraded in germination via the amylolytic pathway. ${ }^{26}$ Therefore, HBCDs posed a severe inhibitory effect on seed germination most probably because they damaged the starch or depressed amylase activity.

The inhibition indices were in the order $\alpha$-HBCD $>\beta$ $\mathrm{HBCD}>\gamma$-HBCD after treatment with the exception of the SB and RE for the $72 \mathrm{~h}$ treatment (Table 1). For example, the inhibition rate of GER for $\alpha$-HBCD treatment was $29.4 \%$ at 96 h, 2.1 and 2.6 times higher than that of the $\beta$ - and $\gamma$-HBCD treatments, respectively. It is interesting to note that the highest accumulation of $\beta$-HBCD in maize did not induce the maximum toxicity to maize growth, indicating that the toxicity of HBCDs to maize does not solely relate to their accumulation. Furthermore, different diastereomer-specific toxicities of HBCDs have been obtained in different toxicity tests. Du et al. ${ }^{16}$ found that the heart rate in zebrafish embryos decreased at $0.1 \mathrm{mg} \mathrm{L}^{-1} \beta$ - and $\gamma$-HBCD treatments, but no effect was observed in $\alpha$-HBCD treatment until the concentration reached $1.0 \mathrm{mg} \mathrm{L}^{-1}$. On the other hand, 1.0 $\mathrm{mg} \mathrm{L}^{-1} \alpha$ - or $\beta$-HBCD significantly depressed the heart rate in zebrafish larvae at $96 \mathrm{~h}$ postfertilization, whereas $\gamma$-HBCD dramaticlly accelerated the heart rate of larvae. Diastereomerselective toxicities of HBCDs were also observed by Hamers et al. $^{8}$ in which dioxin receptor and androgen receptor antagonistic responses were detected for individual HBCD diastereoisomers, with the highest potency for $\alpha$-HBCD and the least for $\beta$-HBCD. However, the highest estrogen receptor antagonism was found for $\gamma$-HBCD in the same study, and $\beta$ HBCD was the second most potent inhibitor, whereas $\alpha$ HBCD produced no response. Zhang et al. ${ }^{17}$ observed the cytotoxicity in Hep G2 cells in the following order: $\gamma$-HBCD $\geq$ $\beta$-HBCD $>\alpha$-HBCD. The above comparison may suggest that diastereomer-specific toxicity of HBCDs differs greatly between organisms and even between different toxicological targets, possibly because of the spatial configuration of HBCD and the complexity and asymmetric condition of enzymes, glucosides, organic acids, and phytohormones in organisms, and deserves further investigation.

HBCD Induced Generation of ROS in Maize Tissues. Oxidative stress, resulting from the deleterious effects of ROS, is an important phenomenon in plants when exposed to contaminants. ${ }^{27}$ Endogenous ROS produced in vivo have extremely short half-lives and are present in low concentrations, thereby making detection difficult. In the present study, spin trapping followed by EPR analysis was employed to directly observe the formation of free radicals in maize exposed to HBCDs. Typical six-line (triplet of two lines in each) EPR spectra of ROS and PBN adducts were observed in maize tissues after exposure to $2 \mu \mathrm{g} \mathrm{L}^{-1} \mathrm{HBCDs}$ (Figure 2). The

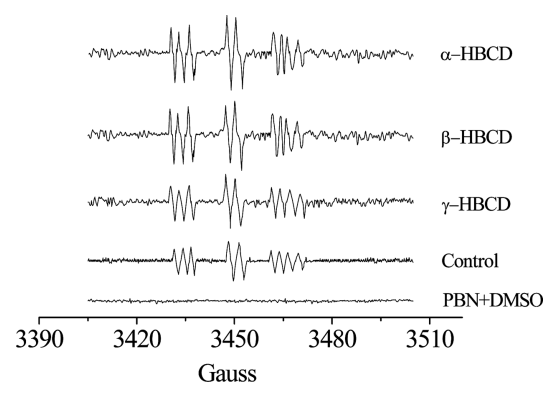

Figure 2. EPR spectra of PBN-radical adducts in maize roots after exposure to $\alpha$-, $\beta$-, and $\gamma$-HBCDs for $12 \mathrm{~h}$.

hyperfine coupling constants of the PBN adducts were $\alpha^{\mathrm{N}}=$ $14.9 \mathrm{G}, \alpha^{\mathrm{H}}=2.9 \mathrm{G}, \alpha^{\mathrm{N}}=16.2 \mathrm{G}, \alpha^{\mathrm{H}}=3.5 \mathrm{G}$, and $g=2.0062$, which correspond to those of $\mathrm{PBN} /$ methoxy radical $\left({ }^{\circ} \mathrm{OCH}_{3}\right)$ and $\mathrm{PBN} /$ methyl radical $\left({ }^{\bullet} \mathrm{CH}_{3}\right)$, respectively. ${ }^{28}$ It was reported that ${ }^{\circ} \mathrm{OH}$ reacted with DMSO to produce the methyl radical $\left({ }^{\bullet} \mathrm{CH}_{3}\right),{ }^{29}$ which was further oxidized to the methoxy radical $\left({ }^{\bullet} \mathrm{OCH}_{3}\right)$ under aerobic conditions. ${ }^{30}$ Methyl gallate could scavenge ${ }^{\bullet} \mathrm{OH}$ but not ${ }^{\bullet} \mathrm{CH}_{3}{ }^{29}$ When $0.2 \mathrm{~mL}$ of $1 \mathrm{M}$ methyl gallate was added to the homogenized plant tissue prior to the addition of PBN and DMSO, the signals of PBN adducts were totally inhibited (data not shown). Therefore, the variations of signal intensity of the PBN-radical adducts in the EPR spectra reflected the generation of ${ }^{\bullet} \mathrm{OH}$, and the ${ }^{\bullet} \mathrm{OH}$ intensity was calculated by the signal intensity of the second couple of the triplet.

Weak ${ }^{\bullet} \mathrm{OH}$ signals were found in the control without $\mathrm{HBCD}$ exposure (Figure 2), indicating ${ }^{\circ} \mathrm{OH}$ generation during normal cellular functions. ${ }^{30}$ All three diastereoisomers induced ${ }^{\bullet} \mathrm{OH}$ generation, and the intensity reached the maximum after $12 \mathrm{~h}$ in roots and after $72 \mathrm{~h}$ in shoots (Figure 3). The increased ${ }^{\circ} \mathrm{OH}$ levels in both roots and shoots followed the order $\alpha$-HBCD > $\beta$-HBCD $>\gamma$-HBCD treatment, consistent with the order of plant development and growth inhibition parameters. The ${ }^{\bullet} \mathrm{OH}$ levels detected in roots exposed to $\alpha$-, $\beta$-, and $\gamma$-HBCDs for 12 $\mathrm{h}$ were $2.0,1.5$, and 1.4 times higher than those in the controls, respectively. $\mathrm{HBCD}$ was reported to produce oxidative stress and induce apoptosis, ${ }^{31}$ and the $\gamma$-HBCD increased the ROS formation more significantly compared to $\alpha$ - and $\beta$-HBCDs in zebrafish embryos. ${ }^{16}$ Oxidative stress is generally generated from the production and accumulation of ROS. ${ }^{32} \cdot \mathrm{OH}$ is the most reactive species among the ROS and will immediately react with surrounding target molecules after generation. The elevated ${ }^{\bullet} \mathrm{OH}$ levels in maize exposed to HBCDs indicated that all three HBCD diastereoisomers induced oxidative destruction to maize, and $\alpha$-HBCD appeared to be more toxic than the other two diastereoisomers. Under normal physiological situation, production and scavenging of ROS are mainly controlled by the antioxidant defense systems, which manage the overall steady-state level of ROS in cells. ${ }^{18}$ The increase of ROS can stimulate antioxidant enzymes of plants with efficient machinery for scavenging the excess ROS. ${ }^{18}$ Therefore, the - $\mathrm{OH}$ intensity started to decrease after $12 \mathrm{~h}$ in roots and after $72 \mathrm{~h}$ in shoots. Another possible factor that may lead to the decrease of ${ }^{\bullet} \mathrm{OH}$ was cell death, which inactivated the production and scavenging of ROS. ${ }^{33}$

HBCD Induced Generation of $\gamma-\mathrm{H} 2 \mathrm{AX}$ in Maize. To investigate whether $\mathrm{HBCD}$ s can induce genotoxicity in maize, the level of phosphorylated histone H2AX was examined. Elevated levels of $\gamma-\mathrm{H} 2 \mathrm{AX}$ foci in both maize roots and shoots 

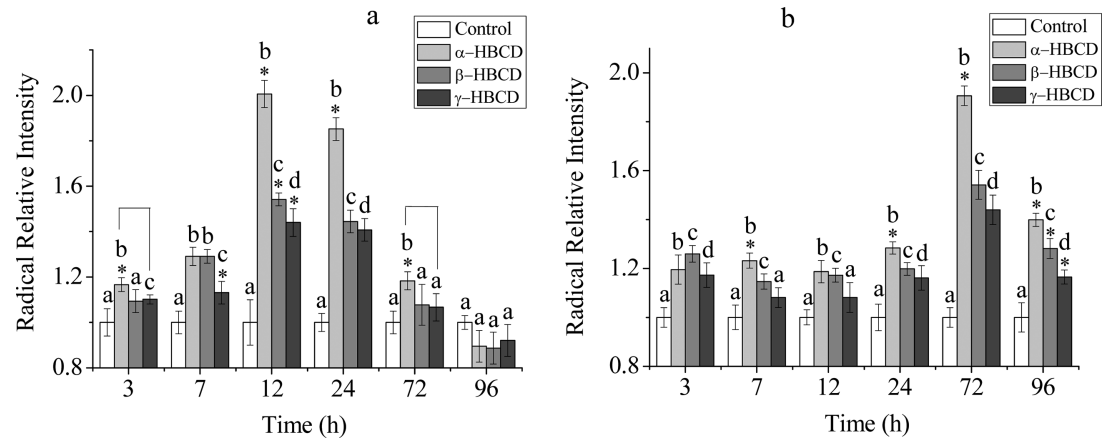

Figure 3. Time-dependent radical relative intensity in roots (a) and shoots (b) of maize exposed to $\alpha$-, $\beta$-, and $\gamma$-HBCDs compared to the controls. * represents statistically significant difference between different diastereoisomers at $p<0.05$. Different letters represent a significant difference compared with control at $p<0.05$ (one-way ANOVA, followed by a post hoc test, LSD).
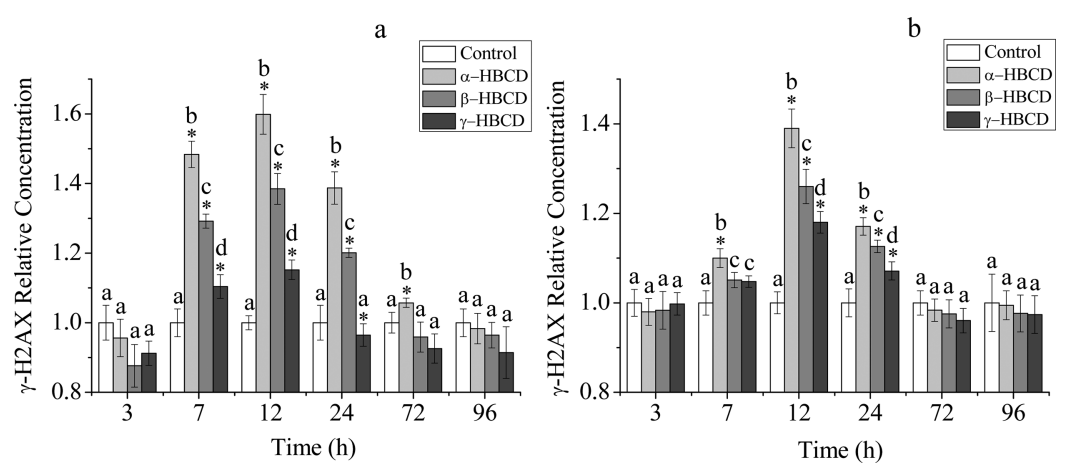

Figure 4. Time-dependent relative $\gamma$-H2AX level in roots (a) and shoots (b) of maize exposed to $\alpha$-, $\beta$-, and $\gamma$-HBCDs compared to the controls. $*$ represents statistically significant difference between different diastereoisomers at $p<0.05$. Different letters represent a significant difference compared with control at $p<0.05$ (one-way ANOVA, followed by a post hoc test, LSD).

Table 2. Relative Inhibition Level of ${ }^{\circ} \mathrm{OH}$ and $\gamma$-H2AX Compared to the Controls after the Addition of ROS Scavengers ${ }^{a}$

\begin{tabular}{|c|c|c|c|c|}
\hline \multirow[b]{2}{*}{ treatment } & \multicolumn{2}{|c|}{${ }^{\circ} \mathrm{OH}$ relative intensity } & \multicolumn{2}{|c|}{$\gamma-\mathrm{H} 2 \mathrm{AX}$ relative concentration } \\
\hline & roots & shoots & roots & shoots \\
\hline control & $1.00 \pm 0.10 \mathrm{a}$ & $1.00 \pm 0.03 a$ & $1.00 \pm 0.02 \mathrm{a}$ & $1.00 \pm 0.01 \mathrm{a}$ \\
\hline$\alpha-\mathrm{HBCD}$ & $2.00 \pm 0.06 \mathrm{a}$ & $1.19 \pm 0.05 \mathrm{a}$ & $1.60 \pm 0.06 \mathrm{a}$ & $1.39 \pm 0.04 \mathrm{a}$ \\
\hline$\beta$-HBCD & $1.54 \pm 0.03 a$ & $1.17 \pm 0.03 a$ & $1.38 \pm 0.04 \mathrm{a}$ & $1.26 \pm 0.04 \mathrm{a}$ \\
\hline$\gamma$-HBCD & $1.44 \pm 0.06 \mathrm{a}$ & $1.08 \pm 0.06 \mathrm{a}$ & $1.19 \pm 0.03 a$ & $1.18 \pm 0.02 \mathrm{a}$ \\
\hline control $+\mathrm{sb}$ & $0.96 \pm 0.08 \mathrm{a}$ & $0.98 \pm 0.04 a$ & $0.98 \pm 0.02 \mathrm{a}$ & $0.97 \pm 0.02 \mathrm{a}$ \\
\hline$\alpha-\mathrm{HBCD}+\mathrm{sb}$ & $1.03 \pm 0.06 \mathrm{~b}$ & $1.02 \pm 0.08 \mathrm{~b}$ & $1.38 \pm 0.02 b$ & $1.21 \pm 0.04 \mathrm{~b}$ \\
\hline$\beta-\mathrm{HBCD}+\mathrm{sb}$ & $1.08 \pm 0.04 \mathrm{~b}$ & $0.94 \pm 0.04 \mathrm{~b}$ & $1.19 \pm 0.04 \mathrm{~b}$ & $1.13 \pm 0.04 \mathrm{~b}$ \\
\hline$\gamma-\mathrm{HBCD}+\mathrm{sb}$ & $1.06 \pm 0.07 \mathrm{~b}$ & $0.97 \pm 0.06 \mathrm{a}$ & $1.08 \pm 0.04 \mathrm{~b}$ & $1.06 \pm 0.02 b$ \\
\hline
\end{tabular}

${ }^{a}$ Different letters represent statistically significant difference between HBCD treatment and HBCD + sodium benzoate $(\mathrm{sb})$ treatment at $p<0.05$.

were observed after exposure to $2 \mu \mathrm{g} \mathrm{L}{ }^{-1} \mathrm{HBCDs}$ for $7 \mathrm{~h}$, and the increased level followed the order $\alpha$-HBCD $>\beta$-HBCD $>\gamma$ $\mathrm{HBCD}$ treatment (Figure 4). The highest $\gamma$-H2AX levels for $\alpha$-, $\beta$-, and $\gamma$-HBCDs exposure were 1.6, 1.4, and 1.2 times higher in roots and 1.4, 1.3, and 1.2 times higher in shoots compared with the levels in the controls, respectively. Several functional studies have already described the relevance of $\mathrm{H} 2 \mathrm{AX}$ in the DSBs responses in human and other mammalian cells; ${ }^{34,35}$ however, limited analyses have been so far performed on plants. Lang et al. $^{36}$ first characterized the expression of H2AXa and $\mathrm{H} 2 \mathrm{AXb}$ in Arabidopsis and noticed the increase of $\gamma-\mathrm{H} 2 \mathrm{AX}$ protein after treatment with the DSB-inducer drug, bleomycin. The difference among the levels of $\gamma-\mathrm{H} 2 \mathrm{AX}$ foci in maize exposed to different HBCD diastereoisomers indicated that the diastereoisomers caused different DNA damage to maize with $\alpha$-diastereoisomer the most serious. The loss of $\gamma$-H2AX foci was observed after $12 \mathrm{~h}$ of exposure to all of the diastereoisomers, which might be ascribed to the repair of DSBs. ${ }^{37}$ Generation of $\gamma$-H2AX foci can localize the DNA damage signaling and repair proteins at the genomic damage sites to repair the damaged DNA fragments. ${ }^{38}$ Macphail et al. ${ }^{39}$ also observed that $\gamma$-H2AX foci number increased in $0.5 \mathrm{~h}$ and then decreased in $4 \mathrm{~h}$ in V79 cells after exposure to X-rays.

To further confirm whether the DNA damage in maize was induced by ${ }^{\circ} \mathrm{OH}$ generation, sodium benzoate, an ${ }^{\circ} \mathrm{OH}$ scavenger, ${ }^{40}$ was added to the exposure solution. No change in $\gamma-\mathrm{H} 2 \mathrm{AX}$ foci level was found in the control without HBCD exposure (Table 2). The application of sodium benzoate significantly reduced ${ }^{\circ} \mathrm{OH}$ generation and inhibited the expression of $\gamma$-H2AX foci $(p<0.05)$ in each diastereoisomer treatment after exposure for $12 \mathrm{~h}$ (Table 2), indicative of the involvement of ${ }^{\bullet} \mathrm{OH}$ generation in the HBCD-induced DNA 
damage in maize. It has been reported that the highly reactive - $\mathrm{OH}$ can react with DNA and cause genetic mutations. ${ }^{41}$ ROSderived DNA oxidation can lead to both the altered bases and the damaged sugar residues, resulting in DNA single- and double-strand breaks. ${ }^{19}$ Although ROS were thought to be a major cause of DNA damage, ${ }^{42}$ many studies draw such conclusions solely on the basis of changes of antioxidative enzyme activities, such as those of superoxide dismutase (SOD) and catalase (CAT) in plants, ${ }^{43}$ and the direct determination of - $\mathrm{OH}$ generation in plants to associate with DNA damage has not been reported. The results of the present study provided some direct evidence that ${ }^{\circ} \mathrm{OH}$ generation can induce the formation of $\gamma-\mathrm{H} 2 \mathrm{AX}$ foci during the DNA DSBs response in maize after exposure to HBCDs. However, the decrease of $\gamma$ $\mathrm{H} 2 \mathrm{AX}$ foci did not result in its return to the control level. We can also notice when comparing the results shown in Figures $3 \mathrm{~b}$ and $4 \mathrm{~b}$ that the reductions of the ${ }^{\circ} \mathrm{OH}$ intensity and the relative $\gamma$-H2AX level in shoots occurred at different exposure times. Therefore, it is expected that in addition to ${ }^{\bullet} \mathrm{OH}$ generation there should be other mechanisms responsible for DNA damage after HBCD exposure.

The results of the present study demonstrated the diastereomer-specific uptake and toxicity of $\mathrm{HBCD}$, which has significant implications for environmental and human health risks. Therefore, the behavior and toxicity of HBCDs in the environment should be evaluated at the diastereoisomeric level.

\section{AUTHOR INFORMATION}

\section{Corresponding Author}

*Phone: 86-010-62849683. Fax: 86-010-62923563. E-mail: szzhang@rcees.ac.cn.

\section{Funding}

This work was funded by the National Basic Research Program of China (Project 2009CB421603), the National Natural Science Foundation of China (Project 20921063), and the Major Science and Technology Program for Water Pollution Control and Treatment (2009ZX07207-002).

\section{Notes}

The authors declare no competing financial interest.

\section{REFERENCES}

(1) Marvin, C. H.; Tomy, G. T.; Armitage, J. M.; Arnot, J. A.; McCarty, L.; Covaci, A.; Palace, V. Hexabromocyclododecane: current understanding of chemistry, environmental fate and toxicology and implications for global management. Environ. Sci. Technol. 2011, 45, 8613-8623.

(2) BSEF. Major brominated flame retardants volume estimates: total market demand by region in 2001; 2003; www.bsef-site.com/docs/ BFR vols 2001.doc.

(3) Hale, R. C.; La Guardia, M. J.; Harvey, E.; Gaylor, M. O.; Matt, T.; Mainor, T. M. Brominated flame retardant concentrations and trends in abiotic media. Chemosphere 2006, 64, 181-186.

(4) Law, R. J.; Herzke, D.; Harrad, S.; Morris, S.; Bersuder, P.; Allchin, C. R. Levels and trends of HBCD and BDEs in the European and Asian environments, with some information for other BFRs. Chemosphere 2008, 73, 223-241.

(5) Haukås, M.; Mariussen, E.; Ruus, A.; Tollefsen, K. E. Accumulation and disposition of hexabromocyclododecane (HBCD) in juvenile rainbow trout (Oncorhynchus mykiss). Aquat. Toxicol. 2009, 95, 144-151.

(6) de Wit, C. A.; Herzke, D.; Vorkamp, K. Brominated flame retardants in the Arctic environment - trends and new candidates. Sci. Total Environ. 2010, 408, 2885-2918.
(7) Hamers, T.; Kamstra, J. H.; Sonneveld, E.; Murk, A. J.; Kester, M. H.; Andersson, P. L.; Legler, J.; Brouwer, A. In vitro profiling of the endocrine-disrupting potency of brominated flame retardants. Toxicol. Sci. 2006, 92, 157-173.

(8) Reistad, T.; Fonnum, F.; Mariussen, E. Neurotoxicity of the pentabrominated diphenyl ether mixture, DE-71, and hexabromocyclododecane (HBCD) in rat cerebellar granule cells in vitro. Arch. Toxicol. 2006, 80, 785-796.

(9) van der Ven, L. T. M.; Verhoef, A.; van de Kuil, T.; Slob, W.; Leonards, P. E. G.; Visser, T. J.; Hamers, T.; Herlin, M.; Håkansson, H.; Olausson, H.; Piersma, A. H.; Vos, J. G. A 28-day oral dose toxicity study enhanced to detect endocrine effects of hexabromocyclododecane in Wistar rats. Toxicol. Sci. 2006, 94, 281-292.

(10) Tomy, G. T.; Budakowski, W.; Halldorson, T.; Whittle, D. M.; Keir, M. J.; Marvin, C.; MacInnis, G.; Alaee, M. Biomagnification of $\alpha$ and $\gamma$-hexabromocyclododecane isomers in a Lake Ontario food web. Environ. Sci. Technol. 2004, 38, 2298-2303.

(11) Zegers, B. N.; Mets, A.; Van Bommel, R.; Minkenberg, C.; Hamers, T.; Kamstra, J. H.; Pierce, G. J.; Boon, J. P. Levels of hexabromocyclododecane in harbor porpoises and common dolphins from western European seas, with evidence for stereoisomer-specific biotransformation by cytochrome P450. Environ. Sci. Technol. 2005, 39, 2095-2100.

(12) Janák, K.; Covaci, A.; Voorspoels, S.; Becher, G. Hexabromocyclododecane in marine species from the Western Scheldt Estuary: diastereoisomer- and enantiomer-specific accumulation. Environ. Sci. Technol. 2005, 39, 1987-1994.

(13) Thomsen, C.; Molander, P.; Daae, H. L.; Janák, K.; Froshaug, M.; Liane, V. H.; Thorud, S.; Becher, G.; Dybing, E. Occupational exposure to hexabromocyclododecane at an industrial plant. Environ. Sci. Technol. 2007, 41, 5210-5216.

(14) Collins, C.; Fryer, M.; Grosso, A. Plant uptake of non-ionic organic chemicals. Environ. Sci. Technol. 2006, 40, 45-52.

(15) Li, Y. N.; Zhou, Q. X.; Wang, Y. Y.; Xie, X. J. Fate of tetrabromobisphenol $\mathrm{A}$ and hexabromocyclododecane brominated flame retardants in soil and uptake by plants. Chemosphere 2011, 82, 204-209.

(16) Du, M. M.; Zhang, D. D.; Yan, C. Z.; Zhang, X. Developmental toxicity evaluation of three hexabromocyclododecane diastereoisomers on zebrafish embryos. Aquat. Toxicol. 2012, 112-113, 1-10.

(17) Zhang, X. L.; Yang, F. X.; Xu, C.; Liu, W. P.; Wen, S.; Xu, Y. Cytotoxicity evaluation of three pairs of hexabromocyclododecane (HBCD) enantiomers on Hep G2 cell. Toxicol. in Vitro 2008, 22, $1520-1527$.

(18) Mittler, R.; Vanderauwera, S.; Gollery, M.; Van Breusegem, F. Reactive oxygen gene network of plants. Trends Plant Sci. 2004, 9, 490-498.

(19) Roldán-Arjona, T.; Ariza, R. R. Repair and tolerance of oxidative DNA damage in plants. Mutat. Res. Rev. Mutat. Res. 2009, 681, 169179.

(20) Rogakou, E. P.; Boon, C.; Redon, C.; Bonner, W. M. Megabase chromatin domains involved in DNA double-strand breaks in vivo. J. Cell Biol. 1999, 146, 905-915.

(21) Modesti, M.; Kanaar, R. DNA repair: spot(light)s on chromatin. Curr. Biol. 2001, 11, R229-R232.

(22) Hunziker, R. W.; Gonsior, S.; MacGregor, J. A.; Desjardins, D.; Ariano, J.; Friederich, U. Fate and effect of hexabromocyclododecane in the environment. Organohalogen Compd. 2004, 66, 2300-2305.

(23) Zhang, X. L.; Yang, F. X.; Luo, C. H.; Wen, S.; Zhang, X.; Xu, Y. Bioaccumulative characteristics of hexabromocyclododecanes in freshwater species from an electronic waste recycling area in China. Chemosphere 2009, 76, 1572-1578.

(24) Morris, S.; Allchin, C. R.; Zegers, B. N.; Haftka, J. J. H.; Boon, J. P.; Belpaire, C.; Leonards, P. E. G.; van Leeuwen, S. P. J.; de Boer, J. Distribution and fate of HBCD and TBBPA brominated flame retardants in North Sea estuaries and aquatic food webs. Environ. Sci. Technol. 2004, 38, 5497-5504. 
(25) Marvin, C. H.; Tomy, G. T.; Alaee, M.; Macinnis, G. Distribution of hexabromocyclododecane in Detroit River suspended sediments. Chemosphere 2006, 64, 268-275.

(26) Juliano, B. O.; Varner, J. E. Enzymic degradation of starch granules in the cotyledons of germinating peas. Plant Physiol. 1969, 44, 886-892.

(27) Bowler, C.; Van Montagu, M.; Inzé, D. Superoxide dismutase and stress tolerance. Annu. Rev. Plant Physiol. Mol. Biol. 1992, 43, 83116.

(28) Burkitt, M. J.; Mason, R. P. Direct evidence for in vivo hydroxylradical generation in experimental iron overload: an ESR spin-trapping investigation. Proc. Natl. Acad. Sci. U.S.A. 1991, 88, 8440-8444.

(29) Takeshita, K.; Fujii, K.; Anzai, K.; Ozawa, T. In vivo monitoring of hydroxyl radical generation caused by $\mathrm{x}$-ray irradiation of rats using the spin trapping/EPR technique. Free Radical Biol. Med. 2004, 36, $1134-1143$

(30) Yin, Y.; Jia, H. X.; Sun, Y. Y. Bioaccumulation and ROS generation in liver of Carassius auratus, exposed to phenanthrene. Comp. Biochem. Physiol. C: Pharmacol. Toxicol. 2007, 145, 288-293.

(31) Deng, J.; Yu, L. Q.; Liu, C. S.; Yu, K.; Shi, X. J.; Yeung, L. W. Y.; Lam, P. K. S.; Wu, R. S. S.; Zhou, B. S. Hexabromocyclododecaneinduced developmental toxicity and apoptosis in zebrafish embryos. Aquat. Toxicol. 2009, 93, 29-36.

(32) Wang, W. B.; Kim, Y. H.; Lee, H. S.; Kim, K. Y.; Deng, X. P.; Kwak, S. S. Analysis of antioxidant enzyme activity during germination of alfalfa under salt and drought stresses. Plant Physiol. Biochem. 2009, 47, 570-577.

(33) Desikan, R.; Cheung, M. K.; Bright, J.; Henson, D.; Hancock, J. T.; Neill, S. J. ABA, hydrogen peroxide and nitric oxide signalling in stomatal guard cells. J. Exp. Bot. 2004, 55, 205-212.

(34) Rothkamm, K.; Löbrich, M. Evidence for a lack of DNA doublestrand break repair in human cells exposed to very low X-ray doses. Proc. Natl. Acad. Sci. U.S.A. 2003, 100, 5057-5062.

(35) Celeste, A.; Difilippantonio, S.; Difilippantonio, M. J.; Fernandez-Capetillo, O.; Pilch, D. R.; Sedelnikova, O. A.; Eckhaus, M.; Ried, T.; Bonner, W. M.; Nussenzweig, A. H2AX haploinsufficiency modifies genomic stability and tumor susceptibility. Cell 2003, $114,371-383$.

(36) Lang, J.; Smetana, O.; Sanchez-Calderon, L.; Lincker, F.; Genestier, J.; Schmit, A. C.; Houlné, G.; Chabouté, M. E. Plant $\gamma \mathrm{H} 2 \mathrm{AX}$ foci are required for proper DNA DSB repair responses and colocalize with E2F factors. New Phytol. 2012, 194, 353-363.

(37) Redon, C.; Pilch, D.; Rogakou, E.; Sedelnikova, O.; Newrock, K.; Bonner, W. Histone H2A variants H2AX and H2AZ. Curr. Opin. Genet. Dev. 2002, 12, 162-169.

(38) Fernandez-Capetillo, O.; Lee, A.; Nussenzweig, M.; Nussenzweig, A. H2AX: the histone guardian of the genome. DNA Repair 2004, 3, 959-967.

(39) Macphail, S. H.; Banáth, J. P.; Yu, T. Y.; Chu, E. H. M.; Lambur, H.; Olive, P. L. Expression of phosphorylated histone H2AX in cultured cell lines following exposure to X-rays. Int. J. Radiat. Biol. 2003, 79, 351-358.

(40) Chang, H. B.; Lin, C. W.; Huang, H. J. Zinc-induced cell death in rice (Oryza sativa L.) roots. Plant Growth Regul. 2005, 46, 261-266.

(41) Cooke, M. S.; Evans, M. D.; Dizdaroglu, M.; Lunec, J. Oxidative DNA damage: mechanisms, mutation, and disease. FASEB J. 2003, 17, $1195-1214$.

(42) Vanderauwera, S.; Suzuki, N.; Miller, G.; van de Cotte, B.; Morsa, S.; Ravanat, J. L.; Hegie, A.; Triantaphylidès, C.; Shulaev, V.; Van Montagu, M. C. E.; Van Breusegem, F.; Mittler, R. Extranuclear protection of chromosomal DNA from oxidative stress. Proc. Natl. Acad. Sci. U.S.A. 2011, 108, 1711-1716.

(43) Mancini, A.; Buschini, A.; Restivo, F. M.; Rossi, C.; Poli, P. Oxidative stress as DNA damage in different transgenic tobacco plants. Plant Sci. 2006, 170, 845-852. 